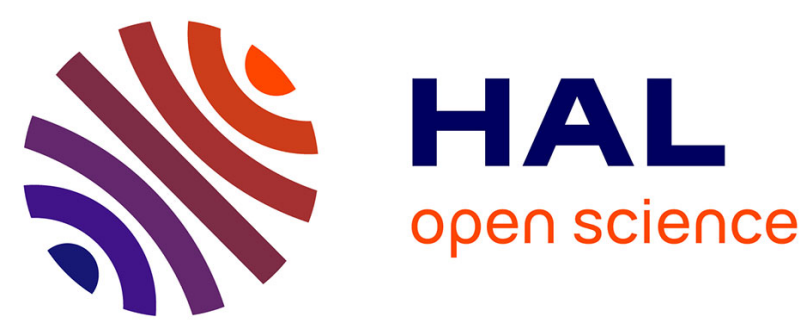

\title{
Cytomegalovirus seropositivity and serointensity are associated with hippocampal volume and verbal memory in schizophrenia and bipolar disorder.
}

Josselin Houenou, Marc-Antoine d'Albis, Claire Daban, Nora Hamdani, Marine Delavest, Jean-Pierre Lépine, François-Eric Vederine, S. Carde, Mohamed Lajnef, Christel Cabon, et al.

\section{To cite this version:}

Josselin Houenou, Marc-Antoine d'Albis, Claire Daban, Nora Hamdani, Marine Delavest, et al.. Cytomegalovirus seropositivity and serointensity are associated with hippocampal volume and verbal memory in schizophrenia and bipolar disorder.. Progress in Neuro-Psychopharmacology and Biological Psychiatry, 2013, 48C, pp.142-148. 10.1016/j.pnpbp.2013.09.003 . inserm-00877593

\section{HAL Id: inserm-00877593 https://www.hal.inserm.fr/inserm-00877593}

Submitted on 28 Oct 2013

HAL is a multi-disciplinary open access archive for the deposit and dissemination of scientific research documents, whether they are published or not. The documents may come from teaching and research institutions in France or abroad, or from public or private research centers.
L'archive ouverte pluridisciplinaire HAL, est destinée au dépôt et à la diffusion de documents scientifiques de niveau recherche, publiés ou non, émanant des établissements d'enseignement et de recherche français ou étrangers, des laboratoires publics ou privés. 
Cytomegalovirus seropositivity and serointensity are associated with hippocampal volume and verbal memory in schizophrenia and bipolar disorder

Houenou J $J^{a, b, c, d^{*}}$, d'Albis $M A^{a, b, c, e}$, Daban $C^{a, b, c}$, Hamdani $N^{a, b, c}$, Delavest $M^{b, f}$, Lepine JP ${ }^{b, f,}$ Vederine $\mathrm{FE}^{\mathrm{a}, \mathrm{c}}$, Carde $\mathrm{S}^{\mathrm{a}, \mathrm{c}}$, Lajnef $\mathrm{M}^{\mathrm{a}, \mathrm{b}}$, Cabon $\mathrm{C}^{\mathrm{g}}$, Dickerson $\mathrm{F}^{\mathrm{h}}$, Yolken $\mathrm{RH}^{\mathrm{h}}$, Tamouza R. ${ }^{\mathrm{i}}$, Poupon $\mathrm{C}^{\mathrm{d}}$, Leboyer $M^{a, b, c, e}$

a) Inserm, U955, Equipe 15 « Psychiatrie Génétique », Créteil, F-94000, France

b) Fondation Fondamental, Créteil, F-94010, France

c) AP-HP, Groupe Henri Mondor - Albert Chenevier, Pôle de psychiatrie, Créteil, F-94000, France

d) Neurospin, CEA Saclay, Gif-Sur-Yvette, France

e) Université Paris Est, Faculté de médecine, Créteil, F-94000, France

f) AP-HP, Service de Psychiatrie, Hôpital Lariboisiere Fernand Widal, Inserm U 705 Cnrs UMR 8206, Paris Diderot University, F-75010, Paris, France

g) Plateforme de ressources biologiques, GH Henri Mondor, Créteil, F-94000, France

h) Stanley Research Program, Sheppard Pratt, Baltimore, MD, USA

i) AP-HP, Laboratoire Jean Dausset d'Immunologie et d'Histocompatibilité \& INSERM, UMRS 940, Hôpital Saint Louis, Univ Paris Diderot, Paris, F-75010, France

*Corresponding author:

Dr Josselin Houenou, AP-HP, Groupe Henri Mondor - Albert Chenevier, Pôle de psychiatrie, 40 rue de Mesly, Créteil, 94000, France.

Tel : +33149813051

Fax : +33149813059

Email : josselin.houenou@inserm.fr 


\section{ABSTRACT}

Introduction: Cytomegalovirus (CMV) is a member of the herpesviridae family that has a limbic and temporal gray matter tropism. It is usually latent in humans but has been associated with schizophrenia, bipolar disorder and cognitive deficits in some populations. Hippocampal decreased volume and dysfunction play a critical role in these cognitive deficits. We hypothesized that CMV seropositivity and serointensity would be associated with hippocampal volume and cognitive functioning in patients with schizophrenia or bipolar disorder.

Methods: 102 healthy controls, 118 patients with bipolar disorder and 69 patients with schizophrenia performed the California Verbal Learning Test (CVLT) and had blood samples drawn to assess CMV IgG levels. A subgroup of 52 healthy controls, 31 patients with bipolar disorder and 27 patients with schizophrenia underwent T1 MRI for hippocampal volumetry. We analyzed the association between CMV serointensity and seropositivity with hippocampal volume. We also explored the correlation between CMV serointensitiy and seropositivity and CVLT scores.

Results: In both patients groups but not in controls, higher CMV serointensity was significantly associated with smaller right hippocampal volume. Further, in the group of patients with schizophrenia but not bipolar disorder, CMV serointensity was negatively correlated with CVLT scores.

Conclusion: CMV IgG titers are associated with decreased hippocampal volume and poorer episodic verbal memory in patients with schizophrenia or bipolar disorder. The mechanism of this association warrants further exploration.

Keywords: cytomegalovirus, schizophrenia, bipolar disorder, hippocampus, verbal memory 


\section{INTRODUCTION ${ }^{1}$}

Human cytomegalovirus (CMV) is a member of the herpesviridae family. Herpes viruses are large enveloped DNA viruses. CMV is being transmitted by intimate contact with infected excretions such as saliva, urine, cervical and vaginal excretions, semen, breast milk, or blood. Risk factors for CMV exposure are breast-feeding, crowding, increased contact with infants and toddlers, poor hygiene, multiple sex partners and promiscuity (Gaytant et al., 2002). The prevalence of CMV infection in adults is at least $60 \%$ in developed countries and $80 \%$ in developing countries (Gaytant et al., 2002; Staras et al., 2006). CMV is neurotropic and asymptomatic in humans, except in certain conditions (congenital infection, immunodepression) (Bristow et al., 2011). In immunocompetent subjects, CMV infection is considered to be latent, asymptomatic and nonpathogenic. Some authors have nevertheless suggested a neuronal, or at least gray-matter, tropism of CMV during this latent phase (Perron et al., 2009; Shinmura et al., 1997; Tsutsui, 2009; Tsutsui et al., 2005). CMV has an affinity for the limbic structures (Yolken and Torrey, 2008) and for the temporal lobe (Hoffmann et al., 2010) as described for other herpesviruses. Animal models suggest that CMV may persistently infect neuronal cells, with a specific tropism for the hippocampus (Arai et al., 2003; Shinmura et al., 1997).

Several but not all studies have reported an association between CMV antibody status and schizophrenia and bipolar disorder (BD). Elevated levels of CMV antibodies in cerebrospinal fluid of patients with schizophrenia and BD have been observed (Albrecht et al., 1980; Rimon et al., 1986; Torrey et al., 1982). More specifically, CMV may be associated with cognitive deficits in schizophrenia, while such an association is not present in healthy young adults. Shirts et al. reported an association between CMV and Trail Making Test performance in patients with schizophrenia (Shirts et al., 2008). Dickerson et al. reported an association between CMV seropositivity and deficit schizophrenia (Dickerson et al., 2006a). Deficit schizophrenia is a putative schizophrenia subtype characterized by primary and enduring negative symptoms. Patients suffering from deficit schizophrenia have poor cognitive performance (Cascella et al., 2008) and hippocampal dysfunction (Mucci et al., 2007). Interestingly, in healthy elderly subjects, CMV titers were associated with cognitive decline (episodic memory) in a prospective study (Aiello et al., 2006).

Most studies have focused solely on CMV seropositivity as a measure of previous exposure (Dickerson et al., 2006a; Shirts et al., 2008; Watson et al., 2012). But one research group has demonstrated a dose-response relationship between CMV serointensity (titer) and cognition (Aiello et al., 2006). It has been suggested that this association between CMV latent infection and decreased cognitive performance may be mediated by chronic inflammatory response and subsequent decreased hippocampal volume (Almanzar et al., 2005).

Decreased hippocampal volume is consistently described in schizophrenia (Adriano et al., 2012). In $\mathrm{BD}$, hippocampal volume is usually reported normal, but decreased only in the most severe forms of BD (Strasser et al., 2005). Postmortem, spectroscopy and neuropsychological studies also add evidence for alterations in hippocampal structure and function in BD (Frey et al., 2007). Declarative memory impairment is also common in euthymic BD (Bora et al., 2009).

Considering the association of CMV with cognitive deficits in schizophrenia and BD, its gray matter, limbic and temporal affinity, and the known hippocampal dysfunctions in BD and schizophrenia,

\footnotetext{
${ }^{1}$ Abbreviations : CMV : cytomegalovirus ; BD : bipolar disorder ; HC: healthy controls; CVLT: California Verbal Learning Test; CVLT-RC-A: CVLT Recall score for list A; PANSS: Positive and Negative Syndrome Scale; YMRS: Young Mania Rating Scale; MADRS: Montgomery-Asberg Depression Scale
} 
we hypothesized that CMV seropositivity and/or antibody levels would be associated with altered hippocampal volume and function, as measured by a verbal memory test in patients. The CVLT (California Verbal Learning Test) is a widely used test of episodic verbal memory in psychiatric populations and is strongly but not exclusively, related to hippocampal functioning (Alexander et al., 2003; Chepenik et al., 2012; van Erp et al., 2008). We included two groups of patients, schizophrenia and BD, as elevated rates of CMV antibodies do not seem specific to schizophrenia but are also present in patients with BD (Tedla et al., 2011; Torrey et al., 1982).

\section{METHODS}

\subsection{Participants}

We included 102 healthy controls (HC), 69 patients with schizophrenia and 118 patients with BD who underwent the clinical, cognitive and serological assessment ("CVLT sample") (California Verbal Learning Test) (table 1). Among them, 52 HC, 27 patients with schizophrenia and 31 patients with BD additionally underwent an MRI scanning ("MRI sample") (table 2). Patients were recruited from two psychiatry departments of university-affiliated hospitals (Créteil and Paris, France). HC were recruited through advertisements. They differed from the "MRI sample" in the sex ratio and from the "CVLT sample" in age, sex ratio and level of education (table 1 and 2).

Inclusion criteria for study participation were age between 18 and 65, no history of alcohol or drug abuse/dependence, no history of mental retardation, no previous head trauma with loss of consciousness, and no current or past cardiac or neurological disease. We excluded subjects with any significant cerebral anatomic anomaly.

In addition, $\mathrm{HC}$ were free of any personal past or present personal psychiatric disorder and firstdegree family history of schizophrenia, schizoaffective disorder or BD. Participants were not included for MRI if MRI was contraindicated or if pregnant. The study was approved by the local IRB (Henri Mondor Hospital, Créteil, France). After complete description of the study to the subjects, written informed consent was obtained.

\subsection{Clinical and cognitive assessment}

DSM-IV personal and familial diagnoses were assessed using the Diagnostic Interview for Genetic Study (DIGS) and the Family Interview for Genetic Study (FIGS) (Elizabeth, 1992; Nurnberger et al., 1994). All patients had a state evaluation of their symptoms with PANSS, YMRS and MADRS (Kay et al., 1987; Montgomery and Asberg, 1979; Young et al., 1978). The verbal memory evaluation consisted of a California Verbal Learning Test (Delis et al., 1988). We calculated the CVLT Recall for list $A$ (number of total correct answers in list A; CVLT-RC-A) and CVLT-Recognition scores (recognition hits). We chose $1 /$ a total learning score as both short and long delayed recall tests but also total learning scores have been proven associated with hippocampus (Tischler et al., 2006; van Norden et al., 2012; Ystad et al., 2010) 2/ CVLT-Recognition score as neuroimaging evidence indicates that hippocampus is crucial for achieving recognition memory tasks (Heun et al., 2006; Reed and Squire, 1997; Wais et al., 2006).

\subsection{MRI procedure}

All images were acquired on the same Siemens 3T Tim Trio MRI system, equipped with a standard 12-channel head coil) at NeuroSpin (Saclay, France). T1 data were obtained using a 3DT1-weighted sequence $($ voxel size $=1 \times 1 \mathrm{~mm}$, slice thickness $=1.1 \mathrm{~mm}, \mathrm{TR}=2300 \mathrm{~ms}, \mathrm{TE}=2.98 \mathrm{~ms}, \mathrm{FOV}=256$ $\mathrm{mm}, \mathrm{nex}=1,160$ slices, flip angle $\left.=9^{\circ}\right)$. 


\subsection{MRI analysis: T1 data processing}

We applied the algorithm FMRIB's Integrated Registration and Segmentation Tool (FIRST) to segment the hippocampi and separately estimate volumes of left and right hippocampus. FIRST is part of FMRIB's Software Library (FSL 4.1.9; http://www.fmrib.ox.ac.uk/fsl) and semi-automatically performs both registration and segmentation of the mentioned subcortical regions (Patenaude et al., 2011). During registration, the input data (3D T1 images) are transformed to the Montreal Neurological Institute (MNI) 152 standard space, by means of affine transformations based on 12 degrees of freedom. A sub-cortical mask is applied, to exclude voxels outside the subcortical regions. This step is followed by segmentation based on shape models and voxel intensities obtained from manually segmented images from the Center for Morphometric Analysis, Massachusetts General Hospital (Boston, MA, USA). Absolute volumes of subcortical structures are calculated, taking into account the transformations made in the first stage (Patenaude et al., 2011). Finally a boundary correction is used to determine which boundary voxels belong to the structure or not, based on a statistical probability.

As recommended by the authors of FSL (http://fsl.fmrib.ox.ac.uk/fsl/fslwiki/first/UserGuide), we checked all the registrations (on axial, coronal and sagittal views); all segmented subcortical regions were visually checked for gross segmentation errors. No misregistration or gross segmentation errors were found. During this procedure, the authors were blind for the diagnoses. We used this FSL automated segmentation as it has been recently compared with manual segmentation that is currently the gold standard. FSL proved reliable for segmenting hippocampi, with intraclass correlation coefficients $>0.66$, and small difference between mean volumes, both in controls and patients suffering from mood or anxiety disorders (Nugent et al., 2012).

Additionally, we computed total intracranial volumes obtained by the sum of gray matter, white matter and CSF on the segmented images. Segmentation into those compartments was performed with SPM8 "New Segment" Module (Wellcome Department of Cognitive Neurology, London, UK) running on Matlab R2011 (MathWorks, Natick, USA).

\subsection{Biological measurements}

Blood was obtained by forearm vein and drawn in EDTA containing tubes. The samples were centrifuged for $10 \mathrm{~min}$ at $4{ }^{\circ} \mathrm{C}$ and the resulting plasma aliquoted into Eppendorf tubes, which were frozen immediately at $-80^{\circ} \mathrm{C}$.

We employed solid phase immunoassay techniques to measure IgG class antibodies to human CMV in the sera of the study individuals. Details have been previously described (Dickerson et al., 2003). Briefly, the assays were performed by the reaction of diluted aliquots of sera to specific CMV antigens immobilized onto a solid phase surface, with the subsequent quantitation of $\lg$ antibodies by reaction of bound antibodies with enzyme labeled anti-human IgG and enzyme substrate. The optical density of the ensuing enzyme-substrate reaction was quantified by means of spectrophotometric instrumentation. The assays for antibodies to CMV employed antigens derived from virion proteins. Reagents for these assays were obtained from IBL Laboratories, Hamburg Germany. Following the performance of the immunoassay procedures, a ratio was calculated for each sample by dividing the optical density of each sample by that of the mean optical density values of standard sera with defined levels of reactivity. The presence of antibodies to CMV was defined for each participant's sample by the measurement of a ratio greater than a predetermined cut-off level of 1.15. An individual with serum antibodies detected by these methods was defined as having serologic evidence of exposure to that infectious agent.

\subsection{Statistical analysis}

We performed linear regressions between CMV IgG titers and hippocampal volumes. We also 
computed linear regressions between CMV IgG titers and CVLT scores. Age, sex, number of years of education (final grade/graduation reached as a marker of premorbid socio-economic status) were entered as covariates, as they are known to influence brain structure, hippocampal function and CMV seropositivity (Staras et al., 2006). Present symptom scores (PANSS for patients with schizophrenia, MADRS and YMRS for patients with BD) were additionally used as covariates for CVLT analyses. When significant associations were identified, we repeated the regressions in a secondary analysis with total intracranial volume as an additional covariate. Normality of the residues was checked with $\mathrm{QQ}$ plots. We performed t-tests to compare demographics and CMV titers between groups (controls and patients).

We used R statistical package version 2.13.1 for these analyses

\section{RESULTS}

\subsection{Demographics and clinical characteristics}

The socio-demographic and clinical characteristics of the subjects are presented in Tables 1 and 2 . In the "MRI sample", the groups were similar for age, handedness and years of education. They differed for sex, with more women in the $\mathrm{HC}$ group than in the patient groups. Comparison of CMV antibody titers between patients and $\mathrm{HC}$ revealed no statistically significant difference.

In the "CVLT sample", patients with schizophrenia had a lower number of years of education and lower CMV antibody titers than HC. Patients had a lower mean CVLT score than controls. There was no significant correlation between CMV antibody titers and the PANSS total score $(p>0.1)$.

\subsection{Hippocampal Volumes and CMV antibodies}

Within the patients with schizophrenia group, we found a significant negative correlation between CMV IgG antibody titer and right hippocampal volume, with a slope (non standardized beta) of 115 $m m 3$ per unit of CMV antibody titer ( $p=0.037 ; t=-2.24$; see Fig.1). When we compared the groups of seropositive and seronegative patients, the difference was also significant, with CMV positive patients having a mean decrease of $247 \mathrm{~mm} 3$ in the volume of the right hippocampus as compared to the CMV negative group ( $p=0.01 ; t=-2.8)$.

Within the patients with $\mathrm{BD}$, a similar significant negative correlation between CMV IgG antibody titer and right hippocampal volume (non standardized beta of $79 \mathrm{~mm} 3$ per unit of CMV antibody titer; $p=0.044 ; t=-2.1$; see Fig.1). When we compared the groups of seropositive and seronegative patients, the difference was also significant, with CMV positive patients having a mean decrease of $256 \mathrm{~mm} 3$ in the volume of the right hippocampus as compared to the CMV negative patients $(p=0.044 ; t=-2.1)$.

These associations remained significant after adding total intracranial volume as a covariate. Duration of the disease was not significantly associated with hippocampal volume, neither in patients with schizophrenia nor in patients with BD.

In patients, no such significant associations were found between the left hippocampal volume and CMV antibody titers.

No correlations were found between hippocampal volumes and CMV antibody titers in the controls group. 


\subsection{Verbal Episodic Memory (CVLT) and CMV antibodies}

In the larger sample of $102 \mathrm{HC}, 69$ patients with schizophrenia and 118 patients with BD who underwent the clinical, cognitive and serological assessment ("CVLT sample"), we performed the CVLT and the CMV antibody assays.

We found a significant negative correlation between the CVLT recognition score and the CMV antibody titers in the schizophrenia group $(p=0.01 ; t=-2.6)$. This difference was also significant when considering CMV IgG as a dichotomous variable $(p=0.015 ; t=-2.5)$. A trend toward a negative correlation between the CVLT-RC-A and the CMV IgG level was found ( $p=0.06 ; t=-1.9)$.

No such association was found in the patients with BD or in the control group.

\section{DISCUSSION}

In patients with BD or schizophrenia, we found a negative association between CMV seropositivity, serointensity and right hippocampal volume. High CMV serointensity was also correlated with low episodic verbal memory measured with the CVLT scores in patients with schizophrenia. These results were obtained after adjustment for age, sex and education and were not present in $\mathrm{HC}$.

To our knowledge, we are the first to report an association between CMV antibody titers andh decreased hippocampal volume or episodic verbal memory dysfunction in patients with BD or schizophrenia.

CVLT is widely used as a probe of hippocampal function, including in patients with schizophrenia or BD (Chepenik et al., 2012; van Erp et al., 2008). We chose to focus on two CVLT scores only: total learning score and recognition. We used this approach in order to decrease the number of tests to be performed. In addition, all CVLT scores, including learning total score, have been reported to be highly correlated (Ystad et al., 2010).

To date, latent CMV infection is largely considered to be asymptomatic and non-pathogenic. Indeed, in our study, within the control group, we found no association of CMV antibody titers with hippocampal dysfunction or volume change. Nevertheless, a few studies suggest that this may be different in populations liable to brain damage. In a prospective study of healthy elderly subjects, initial CMV titers were associated with a decline in episodic memory (Aiello et al., 2006). The few existing previous studies in schizophrenia show heterogeneous results about the impact of CMV on cognitive function. Shirts and colleagues reported an association of CMV seropositivity with impaired cognitive function in schizophrenia (measured by the Trail Making Test, a composite measure of visual search, working memory, and psychomotor speed) (Shirts et al., 2008). A very recent study found an association between CMV seropositivity and a composite heritable measure of cognitive performance in patients with schizophrenia (Watson et al., 2012). Two other large studies failed to find an association between CMV seropositivity and measures of global cognitive functioning in schizophrenia (Dickerson et al., 2003; Yolken et al., 2011), maybe because the tests used were less sensitive to deficits in verbal memory tests.

Similar to our result, two studies found that another herpesvirus, HSV (Herpes Simplex Virus), is related to cognitive (executive) deficits and gray matter decreases in patients with schizophrenia but not in controls (Prasad et al., 2010; Prasad et al., 2012b; Schretlen et al., 2010). HSV-1 is also associated with cognitive deficits in patients with BD but not (or at a far lesser extent) in HC (Aiello 
et al., 2006; Dickerson et al., 2004; Dickerson et al., 2006b; Gerber et al., 2012).

Therefore, some authors have proposed that patients with schizophrenia and patients with BD displayean increased brain susceptibility/liability to exogenous assaults (Schretlen et al., 2010). Infectious assaults such as CMV or HSV do not cause schizophrenia or BD per se. Rather, schizophrenia and BD may render brains liable to CMV- or HSV-damaging effects that would not be present in HC. Our results support this hypothesis.

Several putative mechanisms may account for this association between CMV serointensity and hippocampal decreased volume and altered function.

First, one can assume a direct effect of CMV on early neurodevelopment. Our finding of a decreased hippocampal volume associated with CMV antibody titers is consistent with the hippocampal tropism of CMV observed in animal models, especially in the latent phase of infection (Arai et al., 2003; Shinmura et al., 1997; Tsutsui et al., 2005). Herpesviruses display a common temporal and particularly hippocampal tropism with hippocampal dysfunction. In HSV encephalitis, hippocampal volume reduction is frequent and memory impairment is a cardinal symptom (Geuze et al., 2005). Intranasal inoculation of mice with HSV-1 resulted in the spread of HSV-1 to the hippocampus, amygdala, midbrain and brainstem via the olfactory bulb (Barnett et al., 1993). Epstein-Barr-Virus infections have also been reported to point to hippocampal damage (Hausler et al., 2002; Kremer et al., 2010). Recent studies highlighted the possible role of HHV-6 in mesial temporal lobe epilepsy with detection of HHV-6 DNA in medial temporal areas (Fotheringham et al., 2007; Niehusmann et al., 2010).

But we think this effect is unlikely in our population. We cannot define the date exposure to CMV in the patients in our sample. But the live birth prevalence of congenital CMV infection in the developed world is below 1\% (Kenneson and Cannon, 2007). In addition, the prevalence of congenital CMV is below $2 \%$ all over the world (Gaytant et al., 2002). Epidemiological studies report that the prevalence of CMV antibodies increases with age ranging from 36\% in 6-11 yearsold children to $90 \%$ in those aged $>80$ years in the US (Staras et al., 2006). These data and other suggest that CMV seroprevalence increases with age throughout the lifespan. Therefore, it seems unlikely that CMV exerts effects on the hippocampus though interference with early neurodevelopment.

A more probable explanation is that the association is related to the immune response to infection by CMV. A general dysregulation of immune response has been observed both in schizophrenia and BD. In schizophrenia, HLA polymorphisms are among the strongest associated loci with liability to disease (Shi et al., 2009; Stefansson et al., 2009). Higher levels of pro-inflammatory cytokines have been frequently reported and anti-inflammatory medications are being assessed in schizophrenia (Mansur et al., 2012). The presence of chronic hippocampal inflammation of schizophrenia has been suggested by a PET study (Doorduin et al., 2009). Similarly, in BD, proinflammatory processes have been observed, such as elevated levels of cytokines, especially II-6. Significant associations have been reported between BD and HLA polymorphisms (Hamdani et al., 2012; Purcell et al., 2009). The chronic systemic inflammation in BD and schizophrenia is a possible trigger for lower hippocampal volumes and poorer cognitive performance (Marsland et al., 2008; Marsland et al., 2006; Mondelli et al., 2010).

In patients, chronic infection with CMV would induce an abnormally elevated production of proinflammatory cytokines that would cause hippocampal damage (Lokensgard et al., 2002). In this model, the latent $\mathrm{CMV}$ infection would trigger a chronic immune response, possibly during its reactivations. A reflect of this activation would be the higher levels of CMV antibodies. The 
deregulation of immune response in $\mathrm{BD}$ and schizophrenia may account for a higher impact of $\mathrm{CMV}$ latent infection on brain tissue in patients relative to controls.

Lastly, we cannot exclude a direct neurotoxic effect of CMV on adult neurons, especially during reactivations. Animal models of CMV infection do not support this hypothesis (Shinmura et al., 1997; Tsutsui et al., 2005). An alternative explanation may be a dysregulation of neurotransmitter signaling due to CMV: some authors have reported that CMV infection inhibits the expression of NMDA receptors in primary neuronal cultures and in the developing mice hippocampus (Kosugi et al., 2005). This disturbance of NMDA signaling linked to CMV may be related to functional alteration of hippocampal function.

The association of higher CMV antibodies titers with smaller hippocampal volume was right-sided. Interestingly, in a prospective study of patients with first-episode psychosis (affective disorder or schizophrenia), baseline right hippocampal volume has been associated with poor outcome at follow-up (de Castro-Manglano et al., 2011).

\section{Limitations}

The association between CMV serointensity and verbal memory performance was only present in patients with schizophrenia. This suggests that the association of CMV antibody titers with damage to hippocampal function may be related to different mechanisms in patients with schizophrenia and BD. This finding needs to be confirmed in larger samples of both populations, including patients with BD with and without psychotic features.

Secondly, we did not correct for multiple comparisons. Nevertheless, the similar associations in different groups of patients (schizophrenia and BD) along with the convergence of data for hippocampal size and function strongly support our results. This limitation should be addressed in a future study with larger statistical power to perform correction for multiple comparisons.

Thirdly, our study was cross sectional by nature. This limits the degree to which causal inferences can be made. In particular, there is evidence that lithium, antipsychotics and antidepressants have an effect on hippocampal volumes (Ebdrup et al., 2011; Moore et al., 2000). The cross sectional design and the multiple (current and past) medication classes taken by the patients, preclude our analyzing these medication effects. Future longitudinal studies may help solve this issue.

Fourthly, we used number of years of education as a proxy for premorbid socioeconomic status. This variable may have been impacted by the onset of the disease. Such an impact, if existent, would be rather small in our study as patients have a mean number of years of education very similar to that of the controls, at least for the "MRI sample". Socioeconomic status is conventionally indicated by the number of years of individual education and occupation (Watson et al., 2012). Occupation is likely to be confounded by the illness status and severity.

Fifthly, raw CMV IgG levels were higher in patients than in controls in the larger sample ("CVLT sample"). Such a result is also present in very recent reports (Watson et al., 2012). This may be linked to several factors but does not modify our conclusions since our main analyses were intragroup correlations. Furthermore, most of the existing studies do not found any association between CMV levels and schizophrenia or BD per se, but with subforms of these diseases (e.g. deficit schizophrenia). This is another argument for a further exploration of CMV in subgroups of patients.

Lastly, we only explored the hippocampal region, as it is a preferential site of infection for CMV and is also crucial for episodic memory processes. However, episodic memory is also dependent on other brain regions such as the right dorsolateral prefrontal cortex (Henson et al., 1999; Johnson et al., 2001; Sowell et al., 2001). We chose to focus on hippocampi as their volumes have 
been shown to be the best predictor of recall and recognition discriminability (Kramer et al., 2005). Nevertheless, future, larger studies should explore this issue.

5. Conclusion and perspectives

In our sample, high CMV IgG titers are associated with both decreased hippocampal volume and poorer episodic verbal memory in patients with schizophrenia or BD. This is the first study to report such an association. The mechanism of the association between CMV antibody titers and hippocampal volume and function warrants further exploration and, if confirmed, may generate novel prophylactic and therapeutic approaches as with other herpesviruses. A recent randomized double-blind placebo-controlled trial using valacyclovir as an add-on to antipsychotics has shown the efficacy of valacyclovir to reduce impairments on some cognitive tasks (Prasad et al., 2012a). If an immune mechanism is confirmed, trials involving anti-inflammatory and cytokine blocking agents may also be considered. Finally, several CMV vaccines are currently under development for immunocompromised individuals (transplant patients, HIV, fetus). Some of these vaccines are already under phase I and phase II clinical trials. But there is no clear prospect of an efficient vaccine in the near future (Schleiss, 2008). In sum, our study opens new potential mechanistic, prophylactic and therapeutic avenues for cognitive deficits in schizophrenia and BD.

Authorship contributions

$J H, M A D, C D, N H, J P L, F D, R H, R T, C P$ and $M L$ designed the study. JH, MAD, CD, NH, MD, FEV, CC, $\mathrm{SC}$ recruited the subjects and collected the data. $\mathrm{JH}, \mathrm{ML}, \mathrm{FD}, \mathrm{RH}, \mathrm{ML}$ managed the literature searches and analyses. Authors JH and ML undertook the statistical analysis and author JH wrote the first draft of the manuscript. All authors contributed to and have approved the final manuscript.

\section{Conflicts of interest}

Robert Yolken is a member of the Stanley Medical Research Institute Board of Directors and Scientific Advisory Board. The terms of this arrangement are being managed by the Johns Hopkins University in accordance with its conflict of interest policies. None of the other authors reports any biomedical financial interests or potential conflicts of interest. 


\section{Acknowledgments}

This work was supported by grants of French National Agency for Research (ANR MNP), Fondation pour la Recherche Médicale (to FEV). These two funding bodies had no role in the study design; collection, analysis and interpretation of the data; writing of the manuscript; and in the decision to submit the paper for publication. The authors would like to thank the patients and controls for their participation. 
Figure 1

Right hippocampal volumes and levels of antiCMV IgG in the schizophrenia group

Figure 2

Right hippocampal volumes and levels of antiCMV IgG in the bipolar disorder group 
Table 1: sociodemographic and clinical characteristics of the "CVLT sample"

\begin{tabular}{|c|c|c|c|c|}
\hline Mean (SD) & Healthy controls & Patients with BD & $\begin{array}{c}\text { Patients with } \\
\text { schizophrenia }\end{array}$ & p-value \\
\hline $\mathrm{N}$ & 102 & 118 & 69 & \\
\hline Age & $37.8(13.9)$ & $45.3(12.6)$ & $39.4(13.1)$ & $\mathrm{p}<0.05$ \\
\hline N males & 65 & 59 & $10.9(2.5)$ & $\mathrm{p}<0.05$ \\
\hline $\begin{array}{c}\text { Years of } \\
\text { education }\end{array}$ & $12.4(2.6)$ & $13.0(2.6)$ & $2.24(1.7)$ & $\mathrm{p}<0.05$ \\
\hline $\begin{array}{c}\text { CMV IgG (optical } \\
\text { density ratio) }\end{array}$ & $2.98(2.0)$ & $2.63(2.0)$ & $23.9(6.8)$ & $\mathrm{NS}$ \\
\hline Age at onset & & $26.3(10.2)$ & $68.0(27.3)$ & \\
\hline PANSS & $7.0(9.3)$ & & $\mathrm{p}<0.05$ \\
\hline MADRS & $3.8(5.4)$ & $38.1(11.5)$ & $\mathrm{p}<0.05$ \\
\hline $\begin{array}{c}\text { YMRS } \\
\text { CVLT Recall for } \\
\text { List A }\end{array}$ & $54.0(8.3)$ & $47.4(11.4)$ & $13.4(2.4)$ & \\
\hline $\begin{array}{c}\text { CVLT Recognition } \\
\text { Score }\end{array}$ & $14.8(1.8)$ & $13.9(2.4)$ & & \\
\hline
\end{tabular}

Table 2: sociodemographic and clinical characteristics of the "MRI sample"

\begin{tabular}{|c|c|c|c|c|}
\hline mean (SD) & $\begin{array}{c}\text { Healthy } \\
\text { controls }\end{array}$ & $\begin{array}{c}\text { Patients with } \\
\text { BD }\end{array}$ & Patients with schizophrenia & p-value \\
\hline N & 52 & 31 & 27 & NS \\
\hline Age & $36.6(11.8)$ & $38.2(12.5)$ & $31.4(9.9)$ & p 0.05 \\
\hline N males & 21 & 21 & 7 & NS \\
\hline N left handed & 2 & 2 & $11.8(2.9)$ & NS \\
\hline Years of education & $12.3(2.9)$ & $13.1(2.4)$ & $2.7(1.7)$ & NS \\
\hline $\begin{array}{c}\text { CMV IgG (optical } \\
\text { density ratio) }\end{array}$ & $2.7(2.0)$ & $2.5(1.9)$ & $3786(506)$ & NS \\
\hline $\begin{array}{c}\text { Right hippocampal } \\
\text { volume (mm3) } \\
\text { Left Hippocampal } \\
\text { Volume (mm3) } \\
\text { Age at onset }\end{array}$ & $3880(475)$ & $4026(370)$ & $3746(509)$ & NS \\
\hline PANSS & $3913(397)$ & $3907(403)$ & $22.7(4.6)$ & \\
\hline MADRS & & $6.2(7.0)$ & $71.6(20.6)$ & \\
\hline YMRS & & $3.9(5.9)$ & & \\
\hline
\end{tabular}




\section{References}

Adriano, F., Caltagirone, C., Spalletta, G., 2012. Hippocampal volume reduction in first-episode and chronic schizophrenia: a review and meta-analysis. Neuroscientist 18, 180-200.

Aiello, A.E., Haan, M., Blythe, L., Moore, K., Gonzalez, J.M., Jagust, W., 2006. The influence of latent viral infection on rate of cognitive decline over 4 years. J Am Geriatr Soc 54, 1046-1054.

Albrecht, P., Torrey, E.F., Boone, E., Hicks, J.T., Daniel, N., 1980. Raised cytomegalovirus-antibody level in cerebrospinal fluid of schizophrenic patients. Lancet 2, 769-772.

Alexander, M.P., Stuss, D.T., Fansabedian, N., 2003. California Verbal Learning Test: performance by patients with focal frontal and non-frontal lesions. Brain 126, 1493-1503.

Almanzar, G., Schwaiger, S., Jenewein, B., Keller, M., Herndler-Brandstetter, D., Wurzner, R., Schonitzer, D., Grubeck-Loebenstein, B., 2005. Long-term cytomegalovirus infection leads to significant changes in the composition of the CD8+ T-cell repertoire, which may be the basis for an imbalance in the cytokine production profile in elderly persons. J Virol 79, 3675-3683.

Arai, Y., Ishiwata, M., Baba, S., Kawasaki, H., Kosugi, I., Li, R.Y., Tsuchida, T., Miura, K., Tsutsui, Y., 2003. Neuronspecific activation of murine cytomegalovirus early gene e1 promoter in transgenic mice. Am J Pathol 163, 643-652.

Barnett, E.M., Cassell, M.D., Perlman, S., 1993. Two neurotropic viruses, herpes simplex virus type 1 and mouse hepatitis virus, spread along different neural pathways from the main olfactory bulb. Neuroscience 57, 1007-1025.

Bora, E., Yucel, M., Pantelis, C., 2009. Cognitive endophenotypes of bipolar disorder: a meta-analysis of neuropsychological deficits in euthymic patients and their first-degree relatives. J Affect Disord 113, 1-20.

Bristow, B.N., O'Keefe, K.A., Shafir, S.C., Sorvillo, F.J., 2011. Congenital cytomegalovirus mortality in the United States, 1990-2006. PLoS Negl Trop Dis 5, e1140.

Cascella, N.G., Testa, S.M., Meyer, S.M., Rao, V.A., Diaz-Asper, C.M., Pearlson, G.D., Schretlen, D.J., 2008. Neuropsychological impairment in deficit vs. non-deficit schizophrenia. J Psychiatr Res 42, 930-937.

Chepenik, L.G., Wang, F., Spencer, L., Spann, M., Kalmar, J.H., Womer, F., Kale Edmiston, E., Pittman, B., Blumberg, H.P., 2012. Structure-function associations in hippocampus in bipolar disorder. Biol Psychol 90, 18-22.

de Castro-Manglano, P., Mechelli, A., Soutullo, C., Landecho, I., Gimenez-Amaya, J.M., Ortuno, F., McGuire, P., 2011. Structural brain abnormalities in first-episode psychosis: differences between affective psychoses and schizophrenia and relationship to clinical outcome. Bipolar Disord 13, 545-555.

Delis, D.C., Freeland, J., Kramer, J.H., Kaplan, E., 1988. Integrating clinical assessment with cognitive neuroscience: construct validation of the California Verbal Learning Test. J Consult Clin Psychol 56, 123-130.

Dickerson, F., Kirkpatrick, B., Boronow, J., Stallings, C., Origoni, A., Yolken, R., 2006a. Deficit schizophrenia: association with serum antibodies to cytomegalovirus. Schizophr Bull 32, 396-400.

Dickerson, F.B., Boronow, J.J., Stallings, C., Origoni, A.E., Cole, S., Krivogorsky, B., Yolken, R.H., 2004. Infection with herpes simplex virus type 1 is associated with cognitive deficits in bipolar disorder. Biol Psychiatry 55, 588-593.

Dickerson, F.B., Boronow, J.J., Stallings, C., Origoni, A.E., Cole, S., Leister, F., Krivogorsky, B., Yolken, R.H., $2006 b$. The catechol O-methyltransferase Val158Met polymorphism and herpes simplex virus type 1 infection are risk factors for cognitive impairment in bipolar disorder: additive gene-environmental effects in a complex human psychiatric disorder. Bipolar Disord 8, 124-132.

Dickerson, F.B., Boronow, J.J., Stallings, C., Origoni, A.E., Ruslanova, I., Yolken, R.H., 2003. Association of serum antibodies to herpes simplex virus 1 with cognitive deficits in individuals with schizophrenia. Arch Gen Psychiatry 60 , 466-472.

Doorduin, J., de Vries, E.F., Willemsen, A.T., de Groot, J.C., Dierckx, R.A., Klein, H.C., 2009. Neuroinflammation in schizophrenia-related psychosis: a PET study. J Nucl Med 50, 1801-1807.

Ebdrup, B.H., Skimminge, A., Rasmussen, H., Aggernaes, B., Oranje, B., Lublin, H., Baare, W., Glenthoj, B., 2011. Progressive striatal and hippocampal volume loss in initially antipsychotic-naive, first-episode schizophrenia patients treated with quetiapine: relationship to dose and symptoms. Int J Neuropsychopharmacol 14, 69-82.

Elizabeth, M., 1992. Family Interview for Genetic Studies. Clinical Neurogenetic Branch, Intramural Research Program, NIMH.

Fotheringham, J., Donati, D., Akhyani, N., Fogdell-Hahn, A., Vortmeyer, A., Heiss, J.D., Williams, E., Weinstein, S., Bruce, D.A., Gaillard, W.D., Sato, S., Theodore, W.H., Jacobson, S., 2007. Association of human herpesvirus-6B with mesial temporal lobe epilepsy. PLoS Med 4, e180.

Frey, B.N., Andreazza, A.C., Nery, F.G., Martins, M.R., Quevedo, J., Soares, J.C., Kapczinski, F., 2007. The role of hippocampus in the pathophysiology of bipolar disorder. Behav Pharmacol 18, 419-430.

Gaytant, M.A., Steegers, E.A., Semmekrot, B.A., Merkus, H.M., Galama, J.M., 2002. Congenital cytomegalovirus infection: review of the epidemiology and outcome. Obstet Gynecol Surv 57, 245-256.

Gerber, S.I., Krienke, U.J., Biedermann, N.C., Grunze, H., Yolken, R.H., Dittmann, S., Langosch, J.M., 2012. Impaired functioning in euthymic patients with bipolar disorder--HSV-1 as a predictor. Prog Neuropsychopharmacol Biol Psychiatry 36, 110-116.

Geuze, E., Vermetten, E., Bremner, J.D., 2005. MR-based in vivo hippocampal volumetrics: 2. Findings in neuropsychiatric disorders. Mol Psychiatry 10, 160-184.

Hamdani, N., Tamouza, R., Leboyer, M., 2012. Immuno- inflammatory markers of bipolar disorder: a review of evidence. Front Biosci (Elite Ed) 4, 2170-2182.

Hausler, M., Ramaekers, V.T., Doenges, M., Schweizer, K., Ritter, K., Schaade, L., 2002. Neurological complications 
of acute and persistent Epstein-Barr virus infection in paediatric patients. J Med Virol 68, 253-263.

Henson, R.N., Shallice, T., Dolan, R.J., 1999. Right prefrontal cortex and episodic memory retrieval: a functional MRI test of the monitoring hypothesis. Brain 122 ( Pt 7), 1367-1381.

Heun, R., Freymann, K., Erb, M., Leube, D.T., Jessen, F., Kircher, T.T., Grodd, W., 2006. Successful verbal retrieval in elderly subjects is related to concurrent hippocampal and posterior cingulate activation. Dement Geriatr Cogn Disord $22,165-172$

Hoffmann, C., Grossman, R., Bokov, I., Lipitz, S., Biegon, A., 2010. Effect of cytomegalovirus infection on temporal lobe development in utero: quantitative MRI studies. Eur Neuropsychopharmacol 20, 848-854.

Johnson, S.C., Saykin, A.J., Flashman, L.A., McAllister, T.W., Sparling, M.B., 2001. Brain activation on fMRI and verbal memory ability: functional neuroanatomic correlates of CVLT performance. J Int Neuropsychol Soc 7, 55-62.

Kay, S.R., Fiszbein, A., Opler, L.A., 1987. The positive and negative syndrome scale (PANSS) for schizophrenia. Schizophr Bull 13, 261-276.

Kenneson, A., Cannon, M.J., 2007. Review and meta-analysis of the epidemiology of congenital cytomegalovirus (CMV) infection. Rev Med Virol 17, 253-276.

Kosugi, I., Kawasaki, H., Tsuchida, T., Tsutsui, Y., 2005. Cytomegalovirus infection inhibits the expression of Nmethyl-D-aspartate receptors in the developing mouse hippocampus and primary neuronal cultures. Acta Neuropathol $109,475-482$.

Kramer, J.H., Rosen, H.J., Du, A.T., Schuff, N., Hollnagel, C., Weiner, M.W., Miller, B.L., Delis, D.C., 2005. Dissociations in hippocampal and frontal contributions to episodic memory performance. Neuropsychology 19, 799805.

Kremer, S., Matern, J.F., Bilger, K., Lioure, B., Fornecker, Y., Stoll-Keller, F., Namer, I.J., Dietemann, J.L., FafiKremer, S., 2010. EBV limbic encephalitis after allogenic hematopoietic stem cell transplantation. J Neuroradiol 37 , 189-191.

Lokensgard, J.R., Cheeran, M.C., Hu, S., Gekker, G., Peterson, P.K., 2002. Glial cell responses to herpesvirus infections: role in defense and immunopathogenesis. J Infect Dis 186 Suppl 2, S171-179.

Mansur, R.B., Zugman, A., Asevedo, E.M., da Cunha, G.R., Bressan, R.A., Brietzke, E., 2012. Cytokines in schizophrenia: possible role of anti-inflammatory medications in clinical and preclinical stages. Psychiatry Clin Neurosci 66, 247-260.

Marsland, A.L., Gianaros, P.J., Abramowitch, S.M., Manuck, S.B., Hariri, A.R., 2008. Interleukin-6 covaries inversely with hippocampal grey matter volume in middle-aged adults. Biol Psychiatry 64, 484-490.

Marsland, A.L., Petersen, K.L., Sathanoori, R., Muldoon, M.F., Neumann, S.A., Ryan, C., Flory, J.D., Manuck, S.B., 2006. Interleukin-6 covaries inversely with cognitive performance among middle-aged community volunteers. Psychosom Med 68, 895-903.

Mondelli, V., Pariante, C.M., Navari, S., Aas, M., D'Albenzio, A., Di Forti, M., Handley, R., Hepgul, N., Marques, T.R., Taylor, H., Papadopoulos, A.S., Aitchison, K.J., Murray, R.M., Dazzan, P., 2010. Higher cortisol levels are associated with smaller left hippocampal volume in first-episode psychosis. Schizophr Res 119, 75-78.

Montgomery, S.A., Asberg, M., 1979. A new depression scale designed to be sensitive to change. Br J Psychiatry 134, 382-389.

Moore, G.J., Bebchuk, J.M., Wilds, I.B., Chen, G., Manji, H.K., 2000. Lithium-induced increase in human brain grey matter. Lancet 356, 1241-1242.

Mucci, A., Galderisi, S., Kirkpatrick, B., Bucci, P., Volpe, U., Merlotti, E., Centanaro, F., Catapano, F., Maj, M., 2007. Double dissociation of N1 and P3 abnormalities in deficit and nondeficit schizophrenia. Schizophr Res 92, $252-261$.

Niehusmann, P., Mittelstaedt, T., Bien, C.G., Drexler, J.F., Grote, A., Schoch, S., Becker, A.J., 2010. Presence of human herpes virus 6 DNA exclusively in temporal lobe epilepsy brain tissue of patients with history of encephalitis. Epilepsia 51, 2478-2483.

Nugent, A.C., Luckenbaugh, D.A., Wood, S.E., Bogers, W., Zarate, C.A., Jr., Drevets, W.C., 2012. Automated subcortical segmentation using FIRST: Test-retest reliability, interscanner reliability, and comparison to manual segmentation. Hum Brain Mapp.

Nurnberger, J.I., Jr., Blehar, M.C., Kaufmann, C.A., York-Cooler, C., Simpson, S.G., Harkavy-Friedman, J., Severe, J.B., Malaspina, D., Reich, T., 1994. Diagnostic interview for genetic studies. Rationale, unique features, and training. NIMH Genetics Initiative. Arch Gen Psychiatry 51, 849-859; discussion 863-844.

Patenaude, B., Smith, S.M., Kennedy, D.N., Jenkinson, M., 2011. A Bayesian model of shape and appearance for subcortical brain segmentation. Neuroimage 56, 907-922.

Perron, H., Bernard, C., Bertrand, J.B., Lang, A.B., Popa, I., Sanhadji, K., Portoukalian, J., 2009. Endogenous retroviral genes, Herpesviruses and gender in Multiple Sclerosis. J Neurol Sci 286, 65-72.

Prasad, K.M., Bamne, M.N., Shirts, B.H., Goradia, D., Mannali, V., Pancholi, K.M., Xue, B., McClain, L., Yolken, R.H., Keshavan, M.S., Nimgaonkar, V.L., 2010. Grey matter changes associated with host genetic variation and exposure to Herpes Simplex Virus 1 (HSV1) in first episode schizophrenia. Schizophr Res 118, 232-239.

Prasad, K.M., Eack, S.M., Keshavan, M.S., Yolken, R.H., Iyengar, S., Nimgaonkar, V.L., 2012a. Antiherpes VirusSpecific Treatment and Cognition in Schizophrenia: A Test-of-Concept Randomized Double-Blind Placebo-Controlled Trial. Schizophr Bull.

Prasad, K.M., Watson, A.M., Dickerson, F.B., Yolken, R.H., Nimgaonkar, V.L., 2012b. Exposure to Herpes Simplex Virus Type 1 and Cognitive Impairments in Individuals With Schizophrenia. Schizophr Bull. 
Purcell, S.M., Wray, N.R., Stone, J.L., Visscher, P.M., O'Donovan, M.C., Sullivan, P.F., Sklar, P., 2009. Common polygenic variation contributes to risk of schizophrenia and bipolar disorder. Nature 460, 748-752.

Reed, J.M., Squire, L.R., 1997. Impaired recognition memory in patients with lesions limited to the hippocampal formation. Behav Neurosci 111, 667-675.

Rimon, R., Ahokas, A., Palo, J., 1986. Serum and cerebrospinal fluid antibodies to cytomegalovirus in schizophrenia. Acta Psychiatr Scand 73, 642-644.

Schleiss, M.R., 2008. Cytomegalovirus vaccine development. Curr Top Microbiol Immunol 325, 361-382.

Schretlen, D.J., Vannorsdall, T.D., Winicki, J.M., Mushtaq, Y., Hikida, T., Sawa, A., Yolken, R.H., Dickerson, F.B., Cascella, N.G., 2010. Neuroanatomic and cognitive abnormalities related to herpes simplex virus type 1 in schizophrenia. Schizophr Res 118, 224-231.

Shi, J., Levinson, D.F., Duan, J., Sanders, A.R., Zheng, Y., Pe'er, I., Dudbridge, F., Holmans, P.A., Whittemore, A.S., Mowry, B.J., Olincy, A., Amin, F., Cloninger, C.R., Silverman, J.M., Buccola, N.G., Byerley, W.F., Black, D.W., Crowe, R.R., Oksenberg, J.R., Mirel, D.B., Kendler, K.S., Freedman, R., Gejman, P.V., 2009. Common variants on chromosome 6p22.1 are associated with schizophrenia. Nature 460, 753-757.

Shinmura, Y., Aiba-Masago, S., Kosugi, I., Li, R.Y., Baba, S., Tsutsui, Y., 1997. Differential expression of the immediate-early and early antigens in neuronal and glial cells of developing mouse brains infected with murine cytomegalovirus. Am J Pathol 151, 1331-1340.

Shirts, B.H., Prasad, K.M., Pogue-Geile, M.F., Dickerson, F., Yolken, R.H., Nimgaonkar, V.L., 2008. Antibodies to cytomegalovirus and Herpes Simplex Virus 1 associated with cognitive function in schizophrenia. Schizophr Res 106, 268-274.

Sowell, E.R., Delis, D., Stiles, J., Jernigan, T.L., 2001. Improved memory functioning and frontal lobe maturation between childhood and adolescence: a structural MRI study. J Int Neuropsychol Soc 7, 312-322.

Staras, S.A., Dollard, S.C., Radford, K.W., Flanders, W.D., Pass, R.F., Cannon, M.J., 2006. Seroprevalence of cytomegalovirus infection in the United States, 1988-1994. Clin Infect Dis 43, 1143-1151.

Stefansson, H., Ophoff, R.A., Steinberg, S., Andreassen, O.A., Cichon, S., Rujescu, D., Werge, T., Pietilainen, O.P., Mors, O., Mortensen, P.B., Sigurdsson, E., Gustafsson, O., Nyegaard, M., Tuulio-Henriksson, A., Ingason, A., Hansen, T., Suvisaari, J., Lonnqvist, J., Paunio, T., Borglum, A.D., Hartmann, A., Fink-Jensen, A., Nordentoft, M., Hougaard, D., Norgaard-Pedersen, B., Bottcher, Y., Olesen, J., Breuer, R., Moller, H.J., Giegling, I., Rasmussen, H.B., Timm, S., Mattheisen, M., Bitter, I., Rethelyi, J.M., Magnusdottir, B.B., Sigmundsson, T., Olason, P., Masson, G., Gulcher, J.R., Haraldsson, M., Fossdal, R., Thorgeirsson, T.E., Thorsteinsdottir, U., Ruggeri, M., Tosato, S., Franke, B., Strengman, E., Kiemeney, L.A., Melle, I., Djurovic, S., Abramova, L., Kaleda, V., Sanjuan, J., de Frutos, R., Bramon, E., Vassos, E., Fraser, G., Ettinger, U., Picchioni, M., Walker, N., Toulopoulou, T., Need, A.C., Ge, D., Yoon, J.L., Shianna, K.V., Freimer, N.B., Cantor, R.M., Murray, R., Kong, A., Golimbet, V., Carracedo, A., Arango, C., Costas, J., Jonsson, E.G., Terenius, L., Agartz, I., Petursson, H., Nothen, M.M., Rietschel, M., Matthews, P.M., Muglia, P., Peltonen, L., St Clair, D., Goldstein, D.B., Stefansson, K., Collier, D.A., 2009. Common variants conferring risk of schizophrenia. Nature 460, 744-747.

Strasser, H.C., Lilyestrom, J., Ashby, E.R., Honeycutt, N.A., Schretlen, D.J., Pulver, A.E., Hopkins, R.O., Depaulo, J.R., Potash, J.B., Schweizer, B., Yates, K.O., Kurian, E., Barta, P.E., Pearlson, G.D., 2005. Hippocampal and ventricular volumes in psychotic and nonpsychotic bipolar patients compared with schizophrenia patients and community control subjects: a pilot study. Biol Psychiatry 57, 633-639.

Tedla, Y., Shibre, T., Ali, O., Tadele, G., Woldeamanuel, Y., Asrat, D., Aseffa, A., Mihret, W., Abebe, M., Alem, A., Medhin, G., Habte, A., 2011. Serum antibodies to Toxoplasma gondii and Herpesvidae family viruses in individuals with schizophrenia and bipolar disorder: a case-control study. Ethiop Med J 49, 211-220.

Tischler, L., Brand, S.R., Stavitsky, K., Labinsky, E., Newmark, R., Grossman, R., Buchsbaum, M.S., Yehuda, R., 2006. The relationship between hippocampal volume and declarative memory in a population of combat veterans with and without PTSD. Ann N Y Acad Sci 1071, 405-409.

Torrey, E.F., Yolken, R.H., Winfrey, C.J., 1982. Cytomegalovirus antibody in cerebrospinal fluid of schizophrenic patients detected by enzyme immunoassay. Science 216, 892-894.

Tsutsui, Y., 2009. Effects of cytomegalovirus infection on embryogenesis and brain development. Congenit Anom (Kyoto) 49, 47-55.

Tsutsui, Y., Kosugi, I., Kawasaki, H., 2005. Neuropathogenesis in cytomegalovirus infection: indication of the mechanisms using mouse models. Rev Med Virol 15, 327-345.

van Erp, T.G., Therman, S., Pirkola, T., Tuulio-Henriksson, A., Glahn, D.C., Bachman, P., Huttunen, M.O., Lonnqvist, J., Hietanen, M., Kaprio, J., Koskenvuo, M., Cannon, T.D., 2008. Verbal recall and recognition in twins discordant for schizophrenia. Psychiatry Res 159, 271-280.

van Norden, A.G., de Laat, K.F., Fick, I., van Uden, I.W., van Oudheusden, L.J., Gons, R.A., Norris, D.G., Zwiers, M.P., Kessels, R.P., de Leeuw, F.E., 2012. Diffusion tensor imaging of the hippocampus and verbal memory performance: the RUN DMC study. Hum Brain Mapp 33, 542-551.

Wais, P.E., Wixted, J.T., Hopkins, R.O., Squire, L.R., 2006. The hippocampus supports both the recollection and the familiarity components of recognition memory. Neuron 49, 459-466.

Watson, A.M., Prasad, K.M., Klei, L., Wood, J.A., Yolken, R.H., Gur, R.C., Bradford, L.D., Calkins, M.E., Richard, J., Edwards, N., Savage, R.M., Allen, T.B., Kwentus, J., McEvoy, J.P., Santos, A.B., Wiener, H.W., Go, R.C., Perry, R.T., Nasrallah, H.A., Gur, R.E., Devlin, B., Nimgaonkar, V.L., 2012. Persistent infection with neurotropic herpes viruses 
and cognitive impairment. Psychol Med, 1-9.

Yolken, R.H., Torrey, E.F., 2008. Are some cases of psychosis caused by microbial agents? A review of the evidence. Mol Psychiatry 13, 470-479.

Yolken, R.H., Torrey, E.F., Lieberman, J.A., Yang, S., Dickerson, F.B., 2011. Serological evidence of exposure to Herpes Simplex Virus type 1 is associated with cognitive deficits in the CATIE schizophrenia sample. Schizophr Res 128, 61-65.

Young, R.C., Biggs, J.T., Ziegler, V.E., Meyer, D.A., 1978. A rating scale for mania: reliability, validity and sensitivity. Br J Psychiatry 133, 429-435.

Ystad, M., Eichele, T., Lundervold, A.J., Lundervold, A., 2010. Subcortical functional connectivity and verbal episodic memory in healthy elderly--a resting state fMRI study. Neuroimage 52, 379-388. 
